\title{
Differential DNA Methylation Patterns Define Status Epilepticus and Epileptic Tolerance
}

\author{
Suzanne F. C. Miller-Delaney, ${ }^{1}$ Sudipto Das, ${ }^{2,4}$ Takanori Sano, ${ }^{1}$ Eva M. Jimenez-Mateos, ${ }^{1}$ Kenneth Bryan, ${ }^{2,4}$ \\ Patrick G. Buckley, ${ }^{2,3,4}$ Raymond L. Stallings, ${ }^{2,4}$ and David C. Henshall ${ }^{1}$ \\ Departments of ${ }^{1}$ Physiology and Medical Physics and ${ }^{2}$ Cancer Genetics and ${ }^{3}$ Molecular and Cellular Therapeutics, Royal College of Surgeons in Ireland, \\ Dublin 2, Ireland, and ${ }^{4}$ National Children's Research Centre, Our Lady's Children's Hospital, Dublin 12, Ireland
}

Prolonged seizures (status epilepticus) produce pathophysiological changes in the hippocampus that are associated with large-scale, wide-ranging changes in gene expression. Epileptic tolerance is an endogenous program of cell protection that can be activated in the brain by previous exposure to a non-harmful seizure episode before status epilepticus. A major transcriptional feature of tolerance is gene downregulation. Here, through methylation analysis of 34,143 discrete loci representing all annotated CpG islands and promoter regions in the mouse genome, we report the genome-wide DNA methylation changes in the hippocampus after status epilepticus and epileptic tolerance in adult mice. A total of 321 genes showed altered DNA methylation after status epilepticus alone or status epilepticus that followed seizure preconditioning, with $>\mathbf{9 0} \%$ of the promoters of these genes undergoing hypomethylation. These profiles included genes not previously associated with epilepsy, such as the polycomb gene Phc2. Differential methylation events generally occurred throughout the genome without bias for a particular chromosomal region, with the exception of a small region of chromosome 4, which was significantly overrepresented with genes hypomethylated after status epilepticus. Surprisingly, only few genes displayed differential hypermethylation in epileptic tolerance. Nevertheless, gene ontology analysis emphasized the majority of differential methylation events between the groups occurred in genes associated with nuclear functions, such as DNA binding and transcriptional regulation. The present study reports select, genome-wide DNA methylation changes after status epilepticus and in epileptic tolerance, which may contribute to regulating the gene expression environment of the seizure-damaged hippocampus.

\section{Introduction}

The brain possesses endogenous neuroprotective mechanisms that require forewarning to bring protection optimally to bear. When subjected to an insult that is subthreshold for damage, such as brief ischemia or brief seizures, a coordinated response of gene changes and signaling pathways are activated that render the tissue powerfully refractory against a subsequent and otherwise damaging insult (Gidday, 2006; Dirnagl et al., 2009; JimenezMateos and Henshall, 2009). Termed tolerance, this is an evolutionarily conserved program of cell protection. In epilepsy models, brief seizures triggered by chemoconvulsants or electrical stimulation are the preconditioning stimuli, reducing neuronal death caused by a subsequent episode of status epilepticus (SE). For example, non-convulsive seizures elicited by low-dose systemic kainic acid (KA) prevent hippocampal injury by intraamygdala KA-induced SE in C57BL/6 and SJL mice (Hatazaki et

Received Oct. 14, 2011; revised Nov. 21, 2011; accepted Nov. 30, 2011.

Author contributions: S.F.C.M.-D., R.L.S., and D.C.H. designed research; S.F.C.M.-D., S.D., T.S., E.J.-M., K.B., and P.G.B. performed research; S.F.C.M.-D., S.D., E.J.-M., K.B., P.G.B., R.L.S., and D.C.H. analyzed data; S.F.C.M.-D. and D.C.H. wrote the paper.

This work was supported by Science Foundation Ireland Grants 08/IN.1/B1875 (D.C.H.) and 07/IN.1/B1776 (R.L.S.), Brainwave, and Children's Medical and Research Foundation. We thank James Reynolds for technical support.

Correspondence should be addressed to Dr. David C. Henshall, Department of Physiology and Medical Physics, Royal College of Surgeons in Ireland, Dublin 2, Ireland. E-mail: dhenshall@rcsi.ie.

DOI:10.1523/JNEUROSCI.5180-11.2012

Copyright $\odot 2012$ the authors $\quad 0270-6474 / 12 / 321577-12 \$ 15.00 / 0$ al., 2007; Tanaka et al., 2010). In recent years, our understanding of the molecular processes underlying tolerance has been assisted by microarray profiling, which has revealed large-scale, genomic reprogramming of the response to injury (Stenzel-Poore et al., 2007; Johnson and Simon, 2009). In epileptic tolerance, $73 \%$ of the 565 differentially expressed genes in the hippocampus were downregulated (Jimenez-Mateos et al., 2008). This included genes that encode ion channels, excitatory neurotransmitter receptors, and calcium signaling components, indicating that suppression of excitability- and excitotoxicity- related pathways is the main transcriptional phenotype of epileptic tolerance (Jimenez-Mateos et al., 2008).

Epigenetic processes might play an important role in the regulation of gene expression in tolerance. DNA methylation, which is the covalent attachment of methyl groups $\left(\mathrm{CH}_{3}\right)$ to the cytosine base present in CG dinucleotide-containing regulatory sequences, a process catalyzed by a group of enzymes known as DNA methyl transferases (Dnmts), is of particular interest (Robertson, 2005; Feng and Fan, 2009). Differential DNA methylation of gene promoter regions is responsible, in part, for the modulation of gene expression profiles that promote cell identity and function throughout life (Jaenisch and Bird, 2003). The molecular machinery for DNA methylation and demethylation is expressed and functional in adult brain (Endres et al., 2000; Feng et al., 2010; Guo et al., 2011a). Although originally thought to be a static process after cellular differentiation, DNA methylation can be highly dynamic in the hippocampus in response to neural 
activity (Levenson et al., 2006; Miller and Sweatt, 2007; Guo et al., 2011b). Such epigenetic mechanisms are important for certain plasticity and injury responses in brain, and aberrant methylation profiles are associated with neurodevelopmental, neuropsychiatric, and neurodegenerative disorders (Urdinguio et al., 2009; IraolaGuzman et al., 2011).

Presently, we performed the first genome-wide DNA methylation analysis of SE, contrasting the profile to that in epileptic tolerance. Our analysis reveals that changes in DNA methylation state occurred for 288 genes after SE. Although we hypothesized there would be increased DNA methylation in tolerance, only 15 genes were differentially hypermethylated in this group, although many of these were novel and not previously implicated in tolerance. The results indicate a more limited role than expected for hypermethylation in the mechanism of epileptic tolerance.

\section{Materials and Methods}

Animal model. Animal experiments were performed as described previously (Hatazaki et al., 2007; Jimenez-Mateos et al., 2008) in accordance with the European Communities Council Directive (86/609/EEC) and were reviewed and approved by the Research Ethics Committee of the Royal College of Surgeons in Ireland, under license from the Department of Health, Dublin, Ireland. Adult male mice (C57BL/6, $20-25 \mathrm{~g}$ ) were obtained from Harlan. Animals were group housed in a climate-controlled vivarium on a $12 \mathrm{~h}$ light/dark cycle with food and water provided ad libitum.

Figure $1 A$ illustrates the experimental paradigms. Seizure preconditioning was induced by a single intraperitoneal injection of KA (15 $\mathrm{mg} / \mathrm{kg}$ in $0.2 \mathrm{ml}$ volume) (Ascent Scientific). Sham-preconditioned animals received the same volume of saline (intraperitoneally).

To model epileptic tolerance, SE was induced $24 \mathrm{~h}$ after preconditioning by intra-amygdala microinjection of KA ( $1 \mu \mathrm{g}$ in $0.2 \mu \mathrm{l}$ of PBS). A group of sham-preconditioned mice also underwent SE induced by intra-amygdala KA and served as injury controls. Another group of sham-preconditioned mice received intra-amygdala injection of vehicle and served as non-seizure controls (Fig. 1 A). Lorazepam $(6 \mathrm{mg} / \mathrm{kg}$, i.p.) was administered to all animals $40 \mathrm{~min}$ after intra-amygdala injections to minimize morbidity and mortality from SE.

For comparisons between control and preconditioning, animals were killed at 4, 8, or $24 \mathrm{~h}$. All animals given intra-amygdala injections (control, injury, and tolerance) were killed at $24 \mathrm{~h}$.

Microdissection of CA3. The CA3 subfield of the ipsilateral and contralateral hippocampus was microdissected on dry ice and flash frozen in liquid nitrogen for temporary storage at $-80^{\circ} \mathrm{C}$, as described previously (Hatazaki et al., 2007).

Gene expression analysis. CA3 subfields were microdissected from hippocampus and total RNA extracted using the miRNeasy kit (Qiagen) as per protocol. Double-stranded cDNA was synthesized from DNasetreated total RNA using SuperScript II reverse transcriptase (catalog \#18064-014; Invitrogen). PCR analysis was performed using cDNA
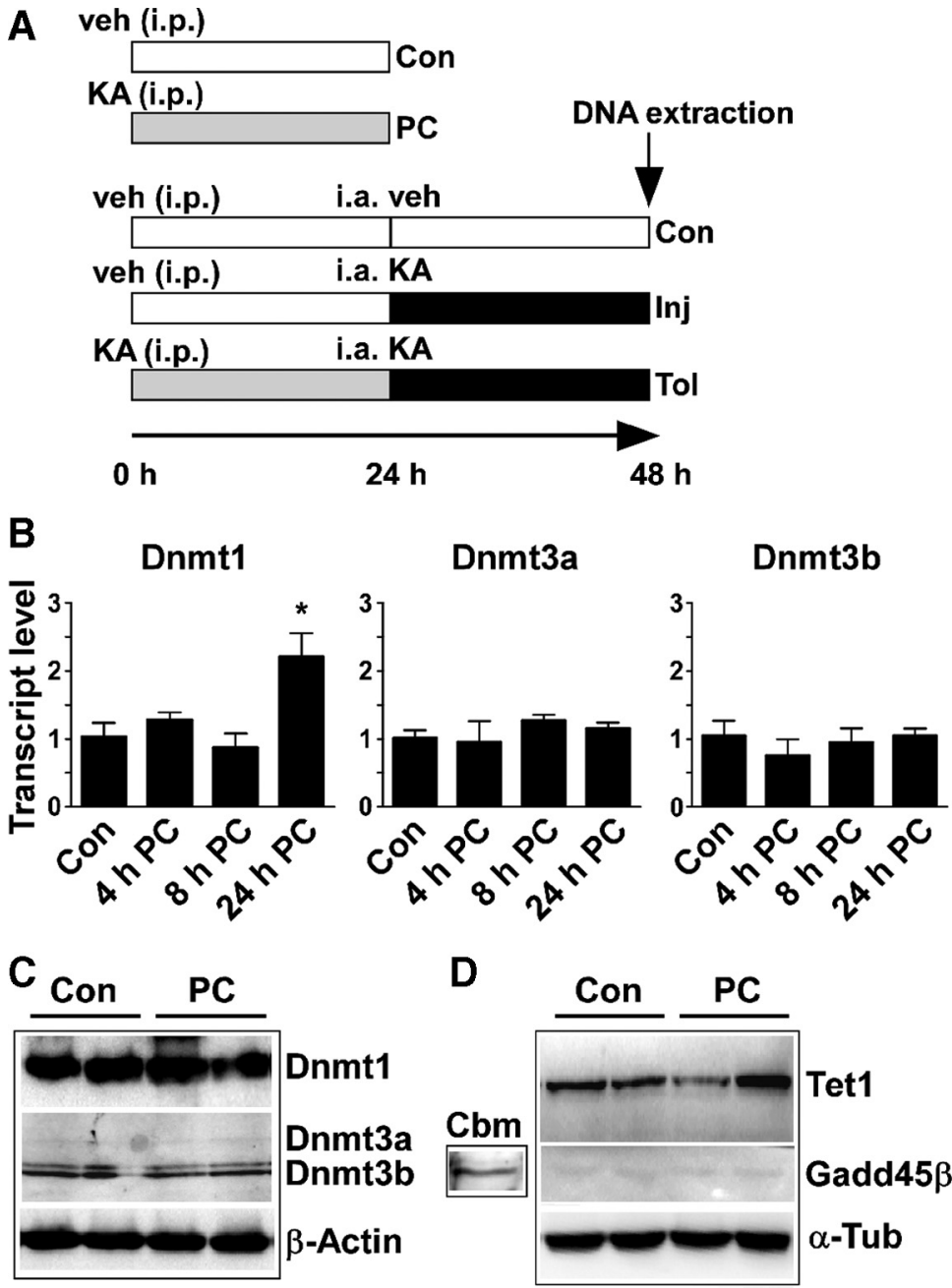

Figure 1. Organization of study groups and expression of DNA methylating and demethylating enzymes after seizure precon列 day 2 by intra-amygdala KA. Samples from these groups are collected $24 \mathrm{~h}$ after intra-amygdala injections. B, Graphs show -time qPCR measurement of the Dnmts in the CA3 subfield 4,8 , and $24 \mathrm{~h}$ after $\mathrm{PC}$. Dnmt 1 levels were significantly increased 政 $24 \mathrm{~h}(n=3$ per group) were analyzed by Western blot. Immunoblots show protein levels of Dnmt $1(\sim 180 \mathrm{kDa}$ ), Tub) are included as a guide to protein loading. Protein levels were unchanged after preconditioning. Box to left of main panel in $D$ shows the signal for Gadd45 $\beta$ in a cerebellum sample.

in triplicate on the 7900 HT Fast Realtime System (Applied Biosystems) for the following genes: Atp2ci (ATPase, $\mathrm{Ca}^{2+}$-sequestering) (Mm00723486_m1), Cpne6 (copine VI) (Mm00464849_m1), Dnmt1 (Mm00599763_m1),Dnmt3a(Mm00432881_m1),Dnmt3b(Mm01240113_ m1), Gtf2i (general transcription factor II I) (Mm00494826_m1), Hmga2 (high mobility group AT-hook 2) (Mm04183367_g1), Hspalb (heat shock protein 1B) (Mm03038954_s1), Map3k7ip2 (Map3k7 binding protein 2) (Mm00663112_m1), Phc2 (Mm00502093_m1), Slc1a6 (solute carrier family 1, member 6) (Mm00436593_m1), and Usp16 (ubiquitinspecific peptidase 16) (Mm00470393_m1). Gapdh (glyceraldehyde-3phosphate dehydrogenase) (Mm99999915_g1) was used for normalization. Minus reverse transcription and non-template controls were routinely used to rule out genomic DNA and cross-well contamination, respectively. A relative fold change in expression was performed using the comparative cycle threshold method $\left(2^{-\Delta \Delta \mathrm{CT}}\right)$.

Western blot analysis. Western blot analysis was performed as described previously (Hatazaki et al., 2007). Hippocampal CA3 subfields 
were homogenized in a lysis buffer, boiled in gel-loading buffer, separated by SDS-PAGE, and transferred onto nitrocellulose membranes. The following primary antibodies were used: Dnmt1 and $\beta$-actin (Sigma-Aldrich), Dnmt3a/b, Tetl (also known as CXXC finger 6), Gadd $45 \beta$ (growth arrest and DNA damage-inducible protein $45 \beta$ ), and $\alpha$-tubulin (Santa Cruz Biotechnology). Membranes were then incubated with horseradish peroxidase-conjugated secondary antibodies (Jackson ImmunoResearch), and bands were visualized using Supersignal West Pico chemiluminescence (Pierce). Images were captured using a FujiFilm LAS-300 (Fuji), and densitometry was performed using AlphaEaseFC4.0 gel-scanning integrated optical density software (Alpha Innotech).

Methylated DNA immunoprecipitation. DNA was isolated from hippocampal CA3 subfields using the DNeasy Blood and Tissue kit (Qiagen) as per the protocol. The CA3 subfields from three mice were pooled for use on a single array. The protocol used for methylation analysis was as described previously (Murphy et al., 2009; Das et al., 2010; Buckley et al., 2011). Briefly, $4 \mu \mathrm{g}$ of sonicated DNA was incubated overnight with 10 $\mu \mathrm{g}$ of anti-5'-methylcytidine antibody (BIMECY-1000; Eurogentec) and immunoprecipitated using Dynabeads (112-02D; Bio Sciences) and a magnetic particle concentrator (DynaMagTM, catalog \#123.21D; Bio Sciences). Methylated DNA immunoprecipitation (MeDIP) and reference control DNA were differentially labeled and hybridized (according to NimbleGen DNA methylation analysis protocol version 6.0) to CpG Island promoter plus arrays from Roche NimbleGen (catalog \#5543649001; Mouse Meth 385K Prom Plus CpG) covering 34,143 loci representing all annotated $\mathrm{CpG}$ islands and promoter regions in the mouse genome. Replicate arrays were performed per condition. Scanning of arrays was performed on an Axon 4000B scanner, and data were processed using GenePix Pro 6.0. Image analysis and peak detection were performed using the methylation application in Nimblescan version 2.4. Methylated peaks were identified using the following parameters: sliding window of $750 \mathrm{bp}, p$ value minimum cutoff $(-\log 10)$ of 2.0 , and a minimum of two probes per peak. Resulting data files were visualized using SignalMap 1.9. Methylation data will be deposited at www.ebi.ac.uk/ arrayexpress (accession number: E-MEXP-3503). Only hypermethylated peaks that were detected in replicate experiments were used for additional analysis.

Real-time qPCR validation of MeDIP results. The MeDIP experiments were validated using a relative quantification approach using SYBR Green master mix (Applied Biosystems, part \#309155). Previously published primers for the Utf1 (Undifferentiated embryonic cell transcription factor 1) unmethylated region (Hiura et al., 2010) were obtained from Sigma-Genosys alongside purpose-designed primers for the H19 (H19 fetal liver mRNA) imprinted control region (forward primer, $5^{\prime}$ CGTTCCCTTGTTGCACATAACA-3'; reverse primer, $5^{\prime}$-CCCCAAAA CCAGCCAGTGT- $\left.3^{\prime}\right)$. The relative level of enrichment $(R Q)$ was calculated for each of the model conditions using the comparative $\mathrm{Ct}$ method. A negative control of immunoprecipitated DNA using normal mouse IgG (catalog \#sc-2025; Santa Cruz Biotechnology) was also included. All real-time qPCR analysis was performed, in duplicate, on the 7900HT Applied Biosystems real-time PCR.

Bioinformatics. Compilation, preprocessing, and analysis of genomic methylation data were performed using in-house developed Java (version 1.6) software. MeDIP probe significances in terms of $p$ values were generated using the Kolmogorov-Smirnov test as implemented by NimbleScan SignalMap software version 1.9. These values were then transformed $(-\log 10)$ to give peak scores. A peak was called when two or more consecutive probes achieved a score of at least 2. Methylation profiles were then generated from the peak score profiles by assessing the presence or absence of a peak over all promoter regions $[-2000$ and $+500 \mathrm{bp}$ around the transcriptional start site (TSS)] and CpG islands. Cluster analysis was then performed using Pearson's correlation as a similarity metric and using complete linkage as cluster distance method. Heat-map visualization was performed using the heatmap. 2 package. Analysis was implemented in the R statistical computing language.

Gene ontology (GO) and functional analyses were assigned by manual interrogation of Entrez Gene (http://www.ncbi.nlm.nih.gov/sites/entrez? $\mathrm{db}=$ gene). Ideogram generation was performed using Idiographica Web-based software (Kin and Ono, 2007). Positional gene enrichment analysis was performed using Web-based software (De Preter et al., 2008).

Bisulfite sequencing. DNA was isolated from CA3 subfields of injury and tolerance mice using the DNeasy Blood and Tissue kit (Qiagen) as per the instructions of the manufacturer. A total of $500 \mathrm{ng}$ of DNA from individual CA3 subfields was bisulfite converted using the EZ DNAmethylation Gold kit (catalog \#D5005 and \#D5006; Zymo), and PCR was performed on $10 \mathrm{ng}$ of the bisulfite-treated DNA as outlined previously (Das et al., 2010). PCR primers were designed using methyl primer express (www.appliedbiosystems.com/methylprimerexpress) and were as follows: Atp2c1, forward primer, $5^{\prime}$-GTATTTGTAAGAGAAATTAGGA GAAG-3' and reverse primer, 5'-TATCTACTCCTACCCCTATTTCC3'; Cpne6, forward primer, 5' -AAGTATTGTGAGAGTGTGTTTTTT-3' and reverse primer, 5'-TCACAAACTCACACATATCTTAAC-3'; Gtf2i, forward primer, 5'-GTTAATTAGGAGCGAAGGAGTAGG-3' and reverse primer, 5'-CCCCAAAATCCACTCTACTTAAA-3'; Hmga2, for-

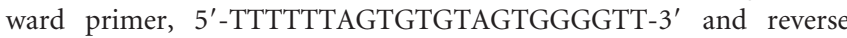
primer, $5^{\prime}$-TCAAATCCTCTAACTTTCACAAA- $3^{\prime}$; and $P h c 2$, forward primer, 5'-GAGGGGTGTAAGGTGATTTTTA-3' and reverse primer, 5'-CAACTTTCCAAACAAACTACCA-3'. PCR products were purified using the QIAquick PCR purification kit (catalog \#28104; Qiagen) as per the instructions of the manufacturer and sequenced in the forward direction at Eurofins MWG Operon.

Data analysis. Data are presented as mean \pm SEM. Gene expression analysis comparisons were made using ANOVA, followed by NewmanKeuls post hoc testing with significance accepted at $p<0.05$.

\section{Results \\ DNA methyltransferase expression in the CA3 subfield of the hippocampus}

We first sought to establish the presence of DNA methyltransferases in the CA3 subfield, which is the site of major neuronal death after intra-amygdala KA-induced SE and which is protected in animals given seizure preconditioning (Hatazaki et al., 2007; Jimenez-Mateos et al., 2008). We were also interested in whether seizure preconditioning caused changes to levels of these genes that might influence how and whether methylation differences occurred when SE is applied. Dnmt1 is thought to contribute to maintenance of DNA methylation, whereas Dnmt3a and Dnmt3b are responsible for de novo DNA methylation (Jaenisch and Bird, 2003).

As expected, expression of Dnmt1, Dnmt3a, and Dnmt3b was detected in control animals (Fig. $1 B$ ). Seizure preconditioning increased Dnmt1 transcript levels in the CA3 subfield at $24 \mathrm{~h}$ (Fig. $1 B)$. No changes were noted for Dnmt $3 a$ and $D n m t 3 b$ expression after seizure preconditioning (Fig. $1 B$ ). To extend this analysis, we examined protein levels of each Dnmt after seizure preconditioning (Fig. 1C). Dnmt1 and Dnmt3b protein was present in control mouse CA3, but Dnmt3a was minimally expressed (Fig. $1 C)$. There were no changes in protein levels for any of the Dnmts in CA3 subfields $24 \mathrm{~h}$ after seizure preconditioning (Fig. $1 C$ and data not shown).

Because DNA demethylation could also contribute to the transcriptional phenotype in epileptic tolerance, we also analyzed samples $24 \mathrm{~h}$ after preconditioning for protein levels of Tet 1 and Gadd $45 \beta$, enzymes implicated in DNA demethylation in brain (Ma et al., 2009; Guo et al., 2011a,b). Tet1 was readily detected in the CA3 subfield of control mice (Fig. $1 D$ ), whereas Gadd $45 \beta$ was essentially undetectable in control CA3 samples but was present in cerebellum (Fig. $1 D$ ). Protein levels of Tet1 and Gadd $45 \beta$ were not different in samples $24 \mathrm{~h}$ after seizure preconditioning (Fig. $1 D$ and data not shown). Thus, the DNA methylation/demethylation apparatus is present in the CA3 subfield of mice but is not noticeably changed by seizure preconditioning. 
A
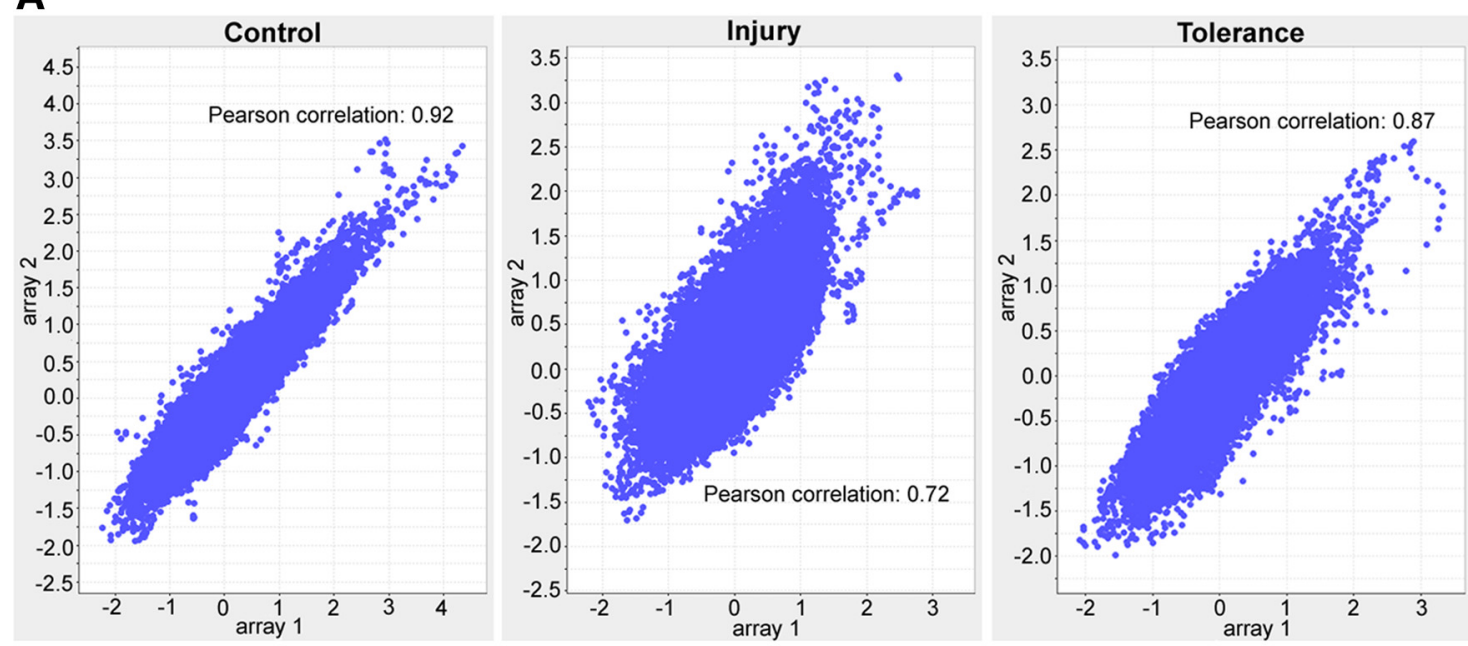

B Summary of array data

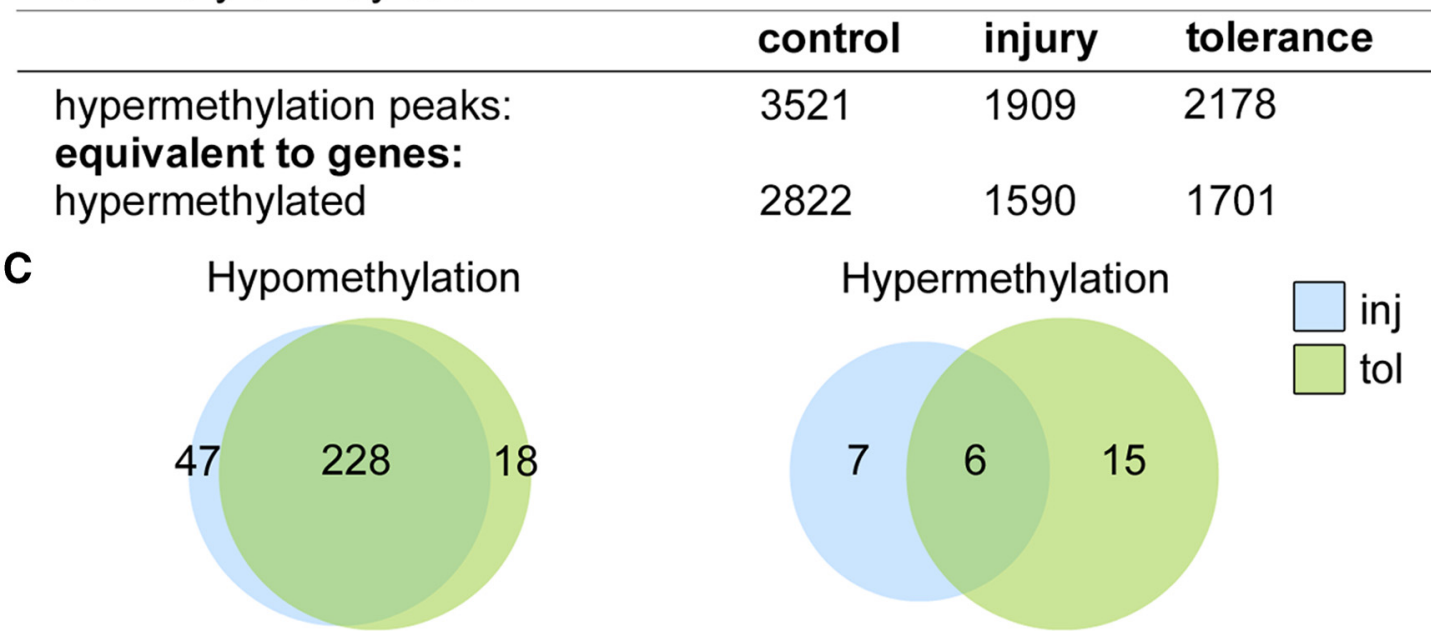

Figure 2. Validation and analysis of methylation profiles. A, Pairwise comparison of MeDIP replicates for control, injury, and tolerance resulted in Pearson's correlation coefficients of $0.92,0.72$, and 0.87 , respectively. $\boldsymbol{B}$, Numbers of common hypermethylation peaks detected in each condition and equivalent gene numbers. $\boldsymbol{C}$, Venn diagrams illustrating the number of genes whose promoters are shared or differentially methylated in injury (inj) and/or tolerance (tol) when compared with controls. Eighteen genes are differentially hypomethylated in tolerance alone, whereas 47 genes are differentially hypomethylated in injury alone. Fifteen genes are differentially hypermethylated in tolerance alone, whereas seven genes are differentially hypermethylated in injury alone.

DNA methylation analysis

We moved next to establish the methylation profiles of the CA3 subfield from non-seizure controls, animals subjected to SE alone (injury), and mice given seizure preconditioning before SE (epileptic tolerance) using MeDIP. Enrichment of immunoprecipitated DNA was confirmed by a qPCR-based assay for the imprinted H19 locus compared with the unmethylated Utf1 locus. The fold enrichment for H19 compared with Utf1 using the comparative Ct method ranged from 6- to 27-fold for each of the samples tested (data not shown).

A pairwise comparison of MeDIP replicates for control, injury, and tolerance resulted in Pearson's correlation coefficients of $0.92,0.72$, and 0.87 , respectively, indicating high reproducibility (Fig. 2A). Methylation peaks that were not detected in both independent arrays were removed from the dataset. The number of hypermethylation peaks conserved between replicates of each condition is shown in Figure $2 B$. The average number of hypermethylated loci (including gene promoters and $\mathrm{CpG}$ islands) detected was 2538 , which corresponds to $7.4 \%$ of the fraction of the genome interrogated (considering 34,143 regions were analyzed on the microarray). Common methylation peaks identified using the NimbleScan 2.4 software in each experiment were mapped to genes using a window of $-2 \mathrm{~kb}$ to $+500 \mathrm{bp}$ relative to the transcriptional start site. This resulted in the identification of 2822, 1590, and 1701 hypermethylated genes in control, injury, and tolerance, respectively (Fig. 2 B). Genes whose methylation status remained unchanged between control and injury or tolerance samples were removed. The remaining dataset contained genes whose promoters were differentially methylated in injury and/or tolerance compared with control (Fig. 2C).

Visualization of the raw data is presented in Figure 3. Hierarchical clustering analysis revealed methylation profiles from each group that validated the paired biological replicates (Fig. 3). Methylation patterns in injury and tolerance animals were more similar to each other than to controls, but each independent sample within a treatment group showed most similarity to its own replicate. Most shared regions of hypomethylation were between injury and tolerance. We also observed a smaller subset of genomic locations that were differentially methylated in injury and tolerance (Fig. 3). Thus, analysis of differential methylation 


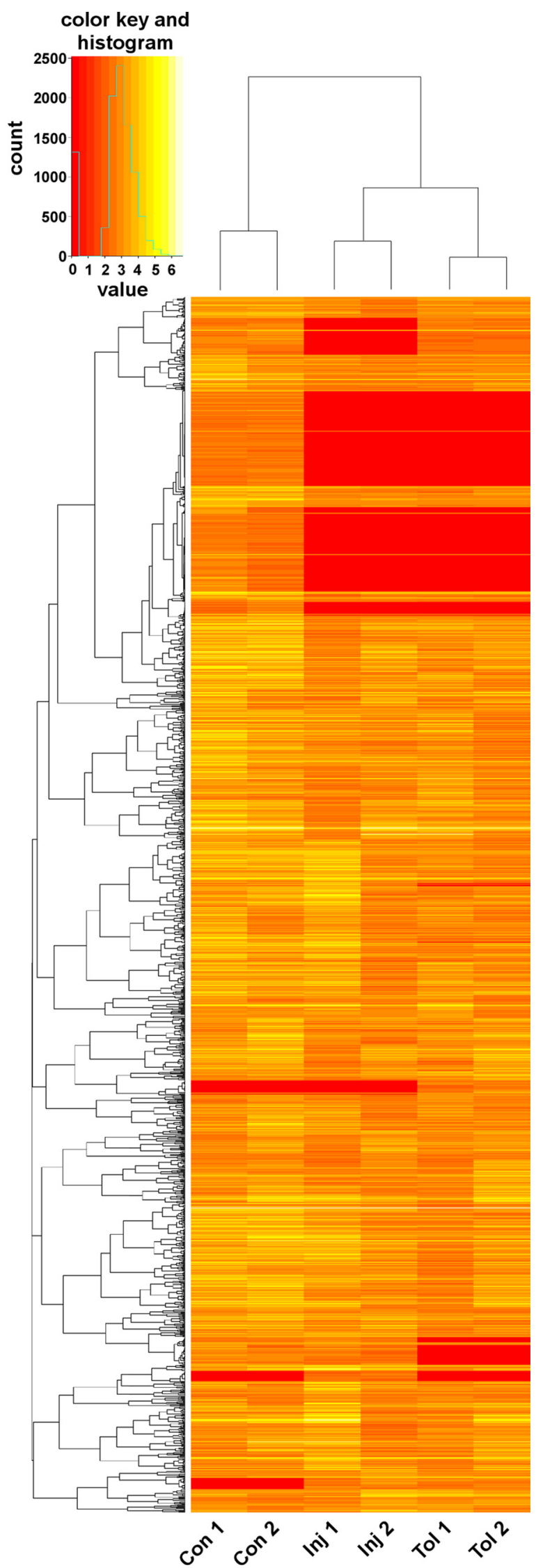

Figure 3. Hierarchical clustering of methylation profiles. Dendrogram showing the hierarchical clustering of raw data methylation profiles between control (Con), injury (Inj), and tolerance (Tol) groups. This provides technical validation in the form of paired biological replicates. Hypomethylation locations are signified by dark red areas, most of which are shared by injury and tolerance in injury and tolerance compared with control highlights unique methylation profiles in each condition.

\section{Promoter methylation profiles after SE and epileptic tolerance}

The more prominent methylation response in injury and tolerance compared with control was differential hypomethylation. Of 293 differentially hypomethylated genes, the majority of hypomethylation events were found to be common occurrences in both injury and tolerance when compared with control (228 genes; 77.8\%) (Fig. 2C and data not shown). Among these were several members of the adam (a disintegrin and metallopeptidase domain), slc (solute carrier), olfr (olfactory receptor), and USP families of genes. A relatively small subgroup of 18 genes $(6.1 \%)$ was found to be differentially hypomethylated in tolerance, whereas $47(16 \%)$ were differentially hypomethylated in injury (Fig. 2C).

Although modest in terms of gene number, the majority of differential hypermethylation events were found to occur in tolerance ( 15 genes of a total of 28; $53.6 \%)$. The promoters of seven genes $(25 \%)$ were differentially hypermethylated in injury alone (Fig. 2C), whereas those of six genes [21.4\%; Abtb1 (Ankyrin repeat \& BTB (POZ) domain containing 1), Acp5 (Acid phosphatase 5, tartrate resistant), Bzrap1 (Benzodiazepine receptor associated protein 1), Hspa12a (Heat Shock Protein 12a), Primal (Proline rich membrane anchor 1), and Zfa (Zinc finger protein, autosomal)] were found to be commonly hypermethylated in both injury and tolerance when compared with control. Genes whose promoters were found to be differentially methylated in tolerance alone are listed in Table 1. Genes whose promoters were found to be differentially methylated in injury alone are listed in Table 2. Notably, few genes present in either dataset have previously been linked with epilepsy.

An interrogation of the previously reported genes differentially downregulated in epileptic tolerance (Jimenez-Mateos et al., 2008) found two of the differentially hypermethylated genes in tolerance:

\section{$\leftarrow$}

groups. Also apparent is a smaller subset of genomic locations that are differentially methylated in injury and tolerance groups and some regions in which there is a clear difference in tolerance from both injury and control. Count signifies the number of $\mathrm{CpGs}$. Value represents the average of the probes for a given region (from $-2 \mathrm{~kb}$ to $+500 \mathrm{bp}$ around the TSS). This value was calculated for each gene that is represented on the histogram. 
Table 1. Genes differentially methylated in epileptic tolerance

\begin{tabular}{|c|c|c|}
\hline Gene ID & $\begin{array}{l}\text { Accession } \\
\text { number }\end{array}$ & Gene title \\
\hline \multicolumn{3}{|l|}{ Hypermethylated } \\
\hline Cpne6 & NM_009947 & Copine VI \\
\hline Gtf2i & NM_010365 & General transcription factor III \\
\hline Hint1 & NM_008248 & Histidine triad nucleotide binding protein 1 \\
\hline Hmga2 & NM_178057 & High mobility group AT-hook 2 \\
\hline Mif & NM_010798 & Macrophage migration inhibitory factor \\
\hline Pold1 & NM_011131 & Polymerase, delta 1, catalytic subunit \\
\hline Rab40c & NM_139154 & Rab40c, member RAS oncogene family \\
\hline Rt11 & NM_184109 & Retrotransposon-like 1 \\
\hline Sae1 & NM_019748 & SUM01 activating enzyme subunit 1 \\
\hline Scrt1 & NM_130893 & Scratch homolog 1 , zinc finger protein \\
\hline Sfmbt2 & NM_177386 & Scm-like with four mbt domains 2 \\
\hline Slc1a6 & NM_009200 & Solute carrier family 1, member 6 \\
\hline Zap70 & NM_009539 & zeta-Chain (TCR) associated protein kinase \\
\hline 4632419K20Rik & NM_199009 & Family with sequence similarity 160 , member $A 2$ \\
\hline 5031439G07Rik & NM_001033273 & RIKEN CDNA 5031439G07 gene \\
\hline \multicolumn{3}{|l|}{ Hypomethylated } \\
\hline Akp5 & NM_007433 & Alkaline phosphatase, placental-like 2 \\
\hline Casp4 & NM_007609 & Caspase 4, apoptosis-related cysteine peptidase \\
\hline Cmtm5 & NM_026066 & $\begin{array}{l}\text { CKLF-like MARVEL transmembrane domain } \\
\text { containing } 5\end{array}$ \\
\hline$C 4 b p$ & NM_007576 & Complement component 4 binding protein \\
\hline Fabp6 & NM_008375 & Fatty acid binding protein 6, ileal (gastrotropin) \\
\hline Kncn & NM_001039124 & Kinocilin \\
\hline Map3k7ip2 & NM_138667 & MAP3K7 binding protein 2 \\
\hline Mrpl53 & NM_026744 & Mitochondrial ribosomal protein L53 \\
\hline Muc19 & NM_207243 & Mucin 19 \\
\hline Myom1 & NM_010867 & Myomesin 1 \\
\hline Olfr1509 & NM_020514 & Olfactory receptor 1509 \\
\hline Olfr653 & NM_147074 & Olfactory receptor 653 \\
\hline $\operatorname{Prg} 3$ & NM_016914 & Proteoglycan 3 \\
\hline Slfn4 & NM_011410 & Schlafen 4 \\
\hline Smgc & NM_198927 & Submandibular gland protein C \\
\hline Usp16 & NM_024258 & Ubiquitin-specific peptidase 16 \\
\hline 1700006J14Rik & NM_177313 & RIKEN CDNA 1700006J14 gene \\
\hline 1810048P08Rik & NM_133717 & RAB43, member RAS oncogene family \\
\hline
\end{tabular}

Cpne6 and Slc1a6. None of the differentially hypomethylated genes were present among the differentially upregulated genes reported previously in epileptic tolerance (Jimenez-Mateos et al., 2008).

\section{Ontology analysis of genes differentially methylated in injury and tolerance}

Bioinformatic analysis of cellular location and molecular function was performed for genes whose promoters were found to be differentially methylated in injury and tolerance. Several striking differences are evident when comparing injury with tolerance (Fig. 4). First, the majority of nucleus-associated differentially methylated genes in injury were hypomethylated, whereas in tolerance the majority of differentially methylated nuclear genes were hypermethylated (Fig. 4). This result corresponds with a difference in the functional profiles of genes differentially methylated in injury and tolerance. The majority of differentially methylated genes that encode DNA binding proteins in injury are found to be hypomethylated (hypomethylated, 7; hypermethylated, 2), whereas in tolerance, all five differentially methylated genes encoding DNA binding proteins are hypermethylated (Fig. 4). Of the differentially methylated genes encoding DNA binding proteins, several are predicted transcriptional regulators. This is of particular relevance when considering the establishment of gene suppression as the major phenotype of epileptic tolerance (Jimenez-Mateos et al.,
Table 2. Genes differentially methylated in injury

\begin{tabular}{|c|c|c|}
\hline Gene ID & $\begin{array}{l}\text { Accession } \\
\text { number }\end{array}$ & Gene title \\
\hline \multicolumn{3}{|l|}{ Hypermethylated } \\
\hline Apoa2 & NM_013474 & Apolipoprotein A-II \\
\hline Atp2c1 & NM_175025 & ATPase, $\mathrm{Ca}^{2+}$-sequestering \\
\hline Clgn & NM_009904 & Calmegin \\
\hline Mta1 & NM_054081 & Metastasis associated 1 \\
\hline Qrfp & NM_183424 & Pyroglutamylated RFamide peptide \\
\hline$T c f 712$ & NM_009333 & Transcription factor 7-like 2 \\
\hline E130203B14Rik & NM_178791 & RIKEN CDNA E130203B14 gene \\
\hline \multicolumn{3}{|l|}{ Hypomethylated } \\
\hline Adam4 & NM_009620 & A disintegrin and metallopeptidase domain 4 \\
\hline Aipl1 & NM_053245 & Aryl hydrocarbon receptor-interacting protein-like 1 \\
\hline Bnc1 & NM_007562 & Basonuclin 1 \\
\hline Cbfa2t3h & NM_009824 & $\begin{array}{l}\text { Core-binding factor, runt domain, alpha subunit 2, } \\
\text { translocated to, } 3 \text { (human) }\end{array}$ \\
\hline Cpxm2 & NM_018867 & Carboxypeptidase X 2 (M14 family) \\
\hline Cyp2c44 & NM_001001446 & $\begin{array}{l}\text { Cytochrome P450, family 2, subfamily c, polypeptide } \\
44\end{array}$ \\
\hline Dzip1 & NM_025943 & DAZ interacting protein 1 \\
\hline Fgf1 & NM_010197 & Fibroblast growth factor 1 \\
\hline Fgl1 & NM_145594 & Fibrinogen-like protein 1 \\
\hline Gent7 & NM_001039560 & Glucosaminyl (N-acetyl) transferase family member 7 \\
\hline Hspa1a & NM_010479 & Heat shock protein 1a \\
\hline Hspalb & NM_010478 & Heat shock protein $1 \mathrm{~b}$ \\
\hline Ifitm6 & NM_001033632 & Interferon-induced transmembrane protein 6 \\
\hline Irf4 & NM_013674 & Interferon regulatory factor 4 \\
\hline Krtap13 & NM_010671 & Keratin-associated protein 13 \\
\hline Krtap6-2 & NM_010673 & Keratin-associated protein 6-2 \\
\hline Lamc1 & NM_010683 & Laminin, gamma 1 \\
\hline Lgals3bp & NM_011150 & Lectin, galactoside-binding, soluble, 3 binding protein \\
\hline Lrfn1 & NM_030562 & $\begin{array}{l}\text { Leucine rich repeat and fibronectin type III domain } \\
\text { containing } 1\end{array}$ \\
\hline Mab2111 & NM_010750 & Mab-21-like 1 \\
\hline Map3k7ip1 & NM_025609 & MAP3K7 binding protein 1 \\
\hline Mib2 & NM_145124 & Mindbomb homolog 2 \\
\hline Ndufb8 & NM_026061 & $\begin{array}{l}\text { NADH dehydrogenase (ubiquinone) } 1 \text { beta } \\
\text { subcomplex } 8\end{array}$ \\
\hline Olfr462 & NM_146411 & Olfactory receptor 462 \\
\hline Pdzd3 & NM_133226 & PDZ domain containing 3 \\
\hline Pfpl & NM_019540 & Pore forming protein-like \\
\hline Phc2 & NM_018774 & Polyhomeotic-like 2 \\
\hline Pik3ca & NM_008839 & $\begin{array}{l}\text { Phosphatidylinositol 3-kinase, catalytic, alpha } \\
\text { polypeptide }\end{array}$ \\
\hline Rai2 & NM_198409 & Retinoic acid induced 2 \\
\hline Rhbdd1 & NM_029777 & Rhomboid domain containing 1 \\
\hline Rnf43 & NM 172448 & Ring finger protein 43 \\
\hline $\operatorname{Sec} 16 A$ & NM_153125 & SEC16 homolog A \\
\hline Serhl & NM_023475 & Serine hydrolase-like \\
\hline S/c38a10 & NM_024249 & Solute carrier family 38, member 10 \\
\hline Sox5 & NM_011444 & SRY-box containing gene 5 \\
\hline Suz12 & NM_199196 & Suppressor of zeste 12 homolog \\
\hline Tcfapze & NM_198960 & Transcription factor AP-2, epsilon \\
\hline TIr12 & NM_205823 & Toll-like receptor 12 \\
\hline Usp18 & NM_011909 & Ubiquitin-specific peptidase 18 \\
\hline Zfp14 & NM_011748 & Zinc finger protein 14 \\
\hline Gm1604 & NM_001033442 & Predicted gene 1604 \\
\hline Gm4894 & NM_177701 & Predicted gene 4894 \\
\hline AU021092 & NM_001033220 & Expressed sequence AU021092 \\
\hline 1700001P01Rik & NM_028156 & RIKEN CDNA 1700001 P01 gene \\
\hline 4632404H12Rik & NM_028726 & RIKEN CDNA 4632404H12 gene \\
\hline 4921510HO8Rik & NM_025724 & RIKEN CDNA $4921510 \mathrm{H} 08$ gene \\
\hline 4932430l15Rik & NM_001033815 & RIKEN CDNA 4932430115 gene \\
\hline
\end{tabular}



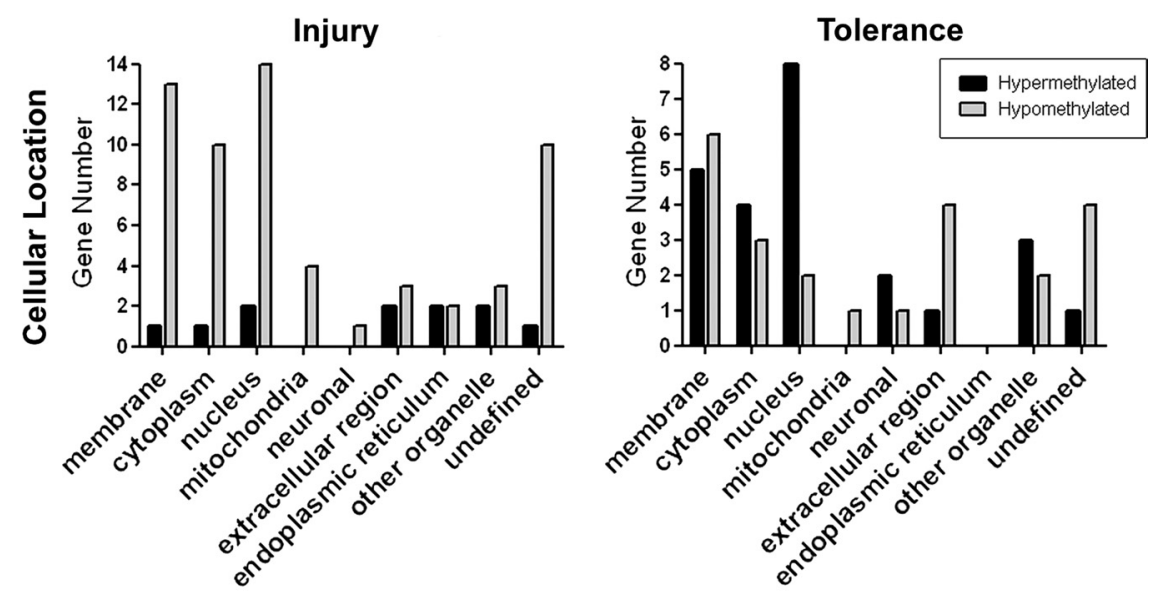

tional gene enrichment analysis (De Preter et al., 2008) was performed on each of the six differentially methylated gene sets (as defined in Fig. 2C). A single region on chromosome 4 (chr 4: 128292690 128430125) was found to be overrepresented when positional gene enrichment analysis was performed on the 47 genes differentially hypomethylated in injury alone (minPi; $p<0.002)$. Only two genes are located in this region, Tlr12 (Toll-like receptor 12) and the polycomb group member $P h c 2$, and both were found to be differentially hypomethylated in injury. No other chromosomal regions were found to be overrepresented in the re-
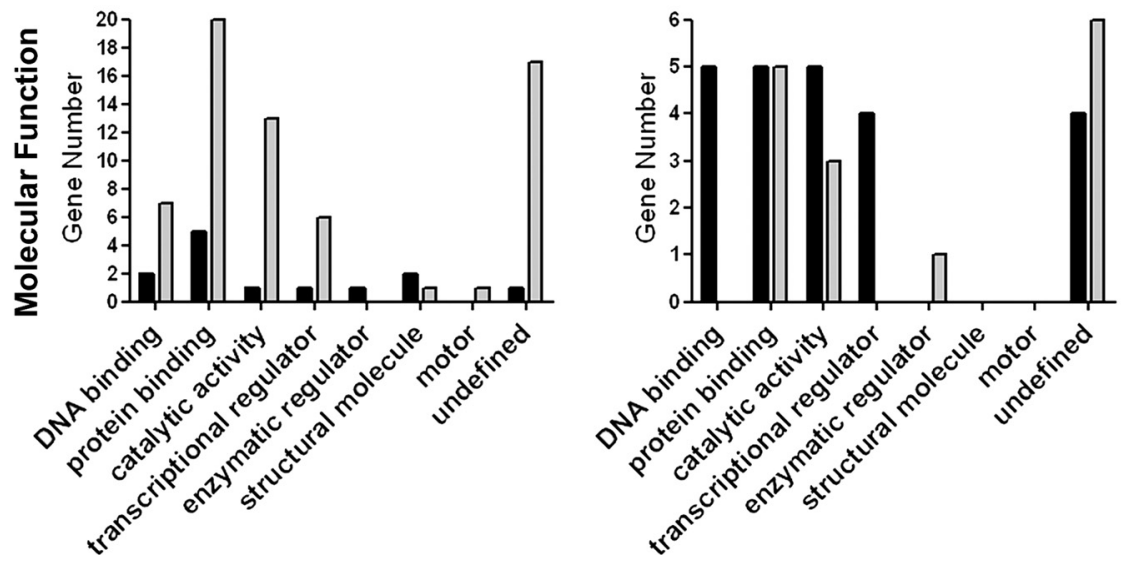

Figure 4. Molecular function and cellular location of differentially methylated genes in injury and tolerance. Bar graphs showing $\mathrm{GO}$ analysis for cellular location (top) and molecular function (bottom) of the differentially methylated genes in injury and tolerance. Note the hypermethylation and hypomethylation differences for genes associated with the nucleus between injury and tolerance.

2008). Nuclear genes whose promoters were differentially methylated in injury include the transcription regulators Mtal (metastasis associated 1; differentially hypermethylated) and $B n c 1$ (basonuclin 1), Cbfa2t3h (core-binding factor runt domain $\alpha$ subunit 2 translocated to 3) (human), Irf4 (interferon regulatory factor 4), Sox5 (SRYbox containing gene 5), Tcfap2e (transcription factor AP-2, epsilon), and Zfp14 (zinc finger protein 14) (all differentially hypomethylated). In epileptic tolerance, the differentially hypermethylated nuclear genes include four transcription regulators: Gtf2i, Hmga2, Scrt1 (Scratch homolog 1), and Sfmbt2 ( $\mathrm{Scm}$-like with four mbt domains 2), as well as the polymerase subunit Pold1 (polymerase delta 1).

Differential methylation of promoters after SE in injury and tolerance occurs throughout the genome

Clustering of hypermethylation sites within the genome has been demonstrated in several cancers (Frigola et al., 2006; Novak et al., 2008; Dallosso et al., 2009; Wu et al., 2010; Buckley et al., 2011). Furthermore, recent reports have shown that nuclear positioning of many genomic regions changes during physiological processes and in disease (Meaburn and Misteli, 2007, 2008) and, during differential activity, in some cases before the start of expression (Ragoczy et al., 2003, 2006).

To visualize the chromosomal location of gene promoters that were differentially methylated in injury or epileptic tolerance and to investigate whether any chromosomes/chromosomal regions were enriched for methylation events, we mapped differentially methylated gene locations (Kin and Ono, 2007) (Fig. 5). Posi- of injury and tolerant mice were separately analyzed using bisulfite sequencing analysis. Genes analyzed included Gtf2i, Cpne6, and Hmga2 (hypermethylated in tolerance), Atp2c1 (hypermethylated in injury), and $P h c 2$ (hypomethylated in injury).

Differential methylation of individual CpG sites was found to be robust and reproducible (Fig. 6, Table 3). The methylation state of individual CpG sites was found to be strongly conserved across biological replicates in a manner consistent with array profiling. In many cases, long stretches of $\mathrm{CpG}$ sites were analyzed by bisulfite sequencing and hypermethylation was confirmed. For example, for $G t f 2 i, \sim 30 \mathrm{CpG}$ sites were hypermethylated across all biological replicates in tolerance compared with conserved hypomethylation of all these sites in injury (Fig. 6A). Similarly for Atp2ci, $18 \mathrm{CpG}$ sites were hypermethylated across all biological replicates in injury compared with conserved hypomethylation of these sites in tolerance (Fig. $6 \mathrm{~B}$ ). Methylation of Cpne6 and Phc2 were also validated as showing the expected methylation differences between injury and tolerance (Fig. 6D,E, Table 3). For Hmga2, scattered CpG sites were found to be methylated in injury as well as tolerance (Fig. 6C). Notably, contralateral CA3 subfields were found to exhibit similar patterns of methylation as the ipsilateral CA3 for all investigated genes (Fig. 6).

\section{Hippocampal expression of genes exhibiting differential methylation in injury and tolerance}

To explore whether promoter methylation had the expected effect on transcription, gene expression analysis was performed on 
a sample of nine genes that were found to exhibit differential promoter methylation in injury or tolerance. These included Atp2c1 (hypermethylated in injury), Hspalb and Phc2 (both hypomethylated in injury), Cpne6, Gtf2i, Hmga2, and Slc1a6 (all hypermethylated in tolerance), and Map3k7ip2 and Usp16 (both hypomethylated in tolerance).

Analysis of the expression of various genes for which differential methylation had been demonstrated indicated complex relationships between methylation profiles and expression trends. For Gtf $2 i$, a hypermethylated gene in tolerance, and Atp2c1, a hypermethylated gene in injury, expression was not different between injury and tolerance groups (Fig. $7 A, B$ ). For $H m g a 2$, another hypermethylated gene in tolerance, the expression level was actually significantly increased in tolerance compared with injury. Bisulfite sequencing had shown hypermethylation of Cpne6 in tolerance (Fig. 6D), and real-time qPCR analysis confirmed on average a 2.4 -fold decrease in Cpne6 transcript levels in tolerance compared with controls (Fig. 6D). However, Cpne6 levels were not lower in tolerance than injury (Fig. 7D).

Expression trends for the polycomb group member $P h c 2$ followed the pattern predicted by differential hypomethylation in injury (Fig. 6E). Expression of the Phc2 transcript was significantly increased in injury compared with tolerance and control (Fig. 7E). No significant difference in Phc2 expression levels was evident between tolerance and control samples. In a second example, methylation array data identified Hspalb (also known as Hsp70) as differentially hypomethylated in injury. Real-time qPCR analysis of Hspalb expression confirmed an 11.27-fold increase in expression in injury compared with control (Fig. 7F). Expression was also increased, however, in tolerance, and no significant difference in Hspalb expression levels was found between tolerance and injury (Fig. 7F). For the remaining interrogated genes, expression trends did not correlate with methylation status being the sole determinant of transcriptional activity. Thus, for Map3k7ip2, Slc1a6, and Usp16, gene expression did not differ significantly between control, injury, or tolerance samples (data not shown).

\section{Discussion}

Here we used genome-wide DNA methylation analysis to profile changes brought about by SE and to test the hypothesis that changes to DNA methylation may contribute to transcriptional downregulation, which is a feature of epileptic tolerance. We found distinct methylation changes in the CA3 subfield of the hippocampus after SE and show multiple DNA methylation differences in epileptic tolerance. Changes in methylation profiles were found to be robust, bilateral, and highly conserved between chromosomes.
Injury

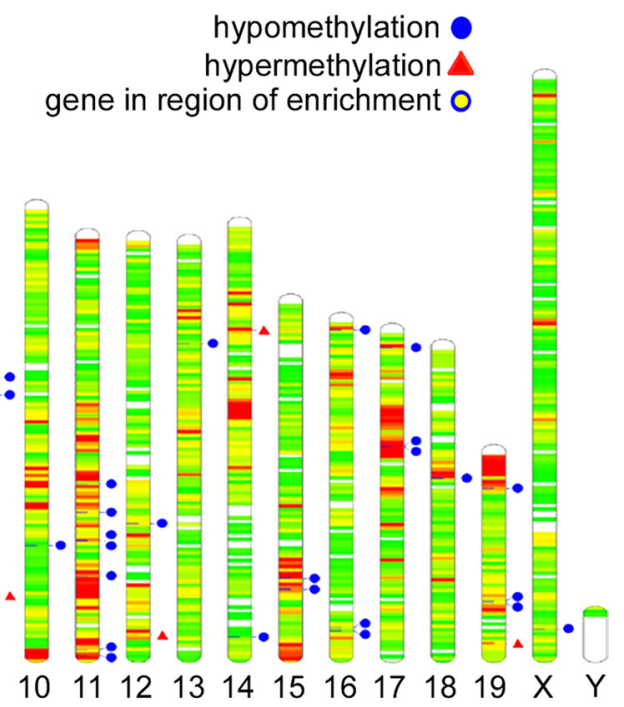

Tolerance

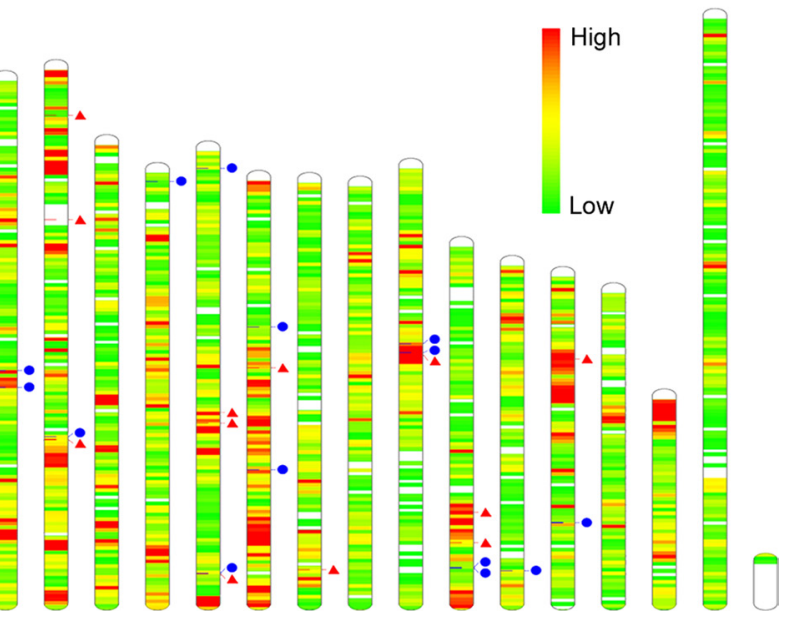

Figure 5. Chromosomal localization of genes differentially methylated in tolerance and injury. Visualization of the location on mouse chromosomes in which sites of differential methylation in injury and tolerance occurred. Hypomethylated genes are hypomethylated in injury showed that a region of chromosome 4 was overrepresented. This region included the neighboring genes TIr12 and PhC2, the location of which are identified by a blue circle with a yellow center. Heat map shows gene density for

biological replicates. Only few genes, however, showed differential hypermethylation in tolerance. This study contributes to our understanding of mechanisms regulating gene expression after SE and the alterations produced when the brain has been exposed previously to seizure activity.

DNA methylation is an important epigenetic mechanism controlling gene expression, and the present study is the first genome-wide DNA methylation analysis of SE. Only a few hundred genes showed differential methylation after SE alone. This supports current ideas on the static nature of the majority of DNA methylation, including in neurological disease (Mill et al., 2008; Morahan et al., 2009; Wu and Zhang, 2010; Guo et al., 2011b). Altogether, 321 genes were differentially methylated in the CA3 subfield of injury and tolerance mice, in contrast to $>2200$ genes for which expression at the mRNA level is altered by twofold or greater in these models (Jimenez-Mateos et al., 2008). 
A

Gtf2i - Hypermethylated in tolerance

CpG site $\quad \begin{array}{llllllllll}1 & 2 & 3 & 4 & 5 & 6 & 7 & 8 & 9 & 101112131415161718192021222324252627282930313233\end{array}$ $\underset{\sim 0.5 \mathrm{~Kb}}{\longrightarrow} \mathrm{TSS}$

Ipsil: Inj $1 \overrightarrow{000000000000000000000000000000 ~}$

Inj 200000000000000000000000000000000

Inj 300000000000000000000000000000000

Tol 1

Tol 2

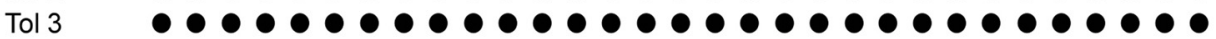

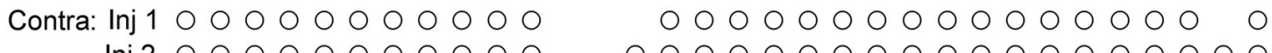

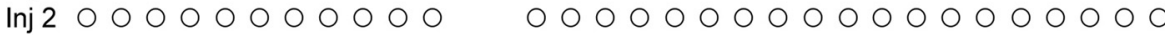

Tol $1 \bullet \bullet \bullet \bullet \bullet \bullet \bullet \bullet \bullet \bullet \bullet \bullet \bullet \bullet \bullet \bullet \bullet \bullet \bullet \bullet \bullet \bullet \bullet \bullet \bullet \bullet \bullet \bullet \bullet \bullet \bullet \bullet$

Tol $2 \bullet \bullet \bullet \bullet \bullet \bullet \bullet \bullet \bullet \bullet \bullet \bullet \bullet \bullet \bullet \bullet \bullet \bullet \bullet \bullet \bullet \bullet \bullet \bullet \bullet \bullet \bullet \bullet \bullet \bullet \bullet \bullet$

B

Atp2c1 - Hypermethylated in injury

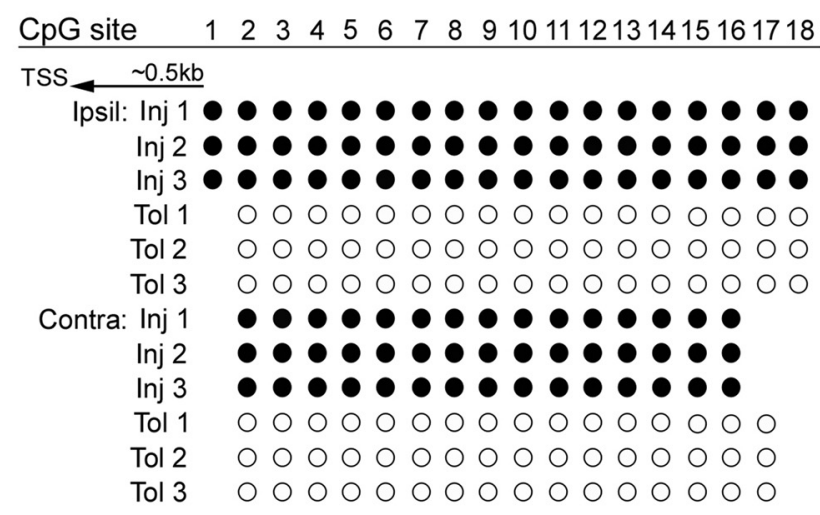

C

Hmga2 - Hypermethylated in tolerance

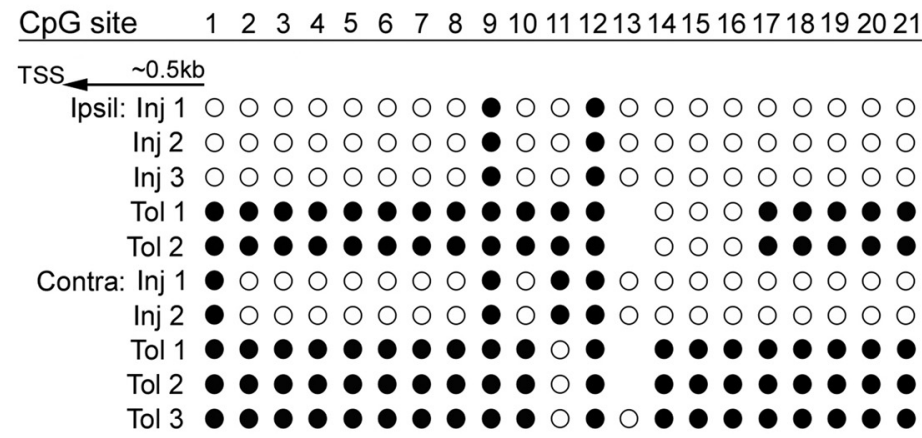

D

Cpne6 - Hypermethylated in tolerance

\begin{tabular}{|c|c|}
\hline CpG site & $\begin{array}{llll}1 & 2 & 3 & 4\end{array}$ \\
\hline & $\sim 1.2 \mathrm{~Kb}$ \\
\hline Ipsil: Inj 1 & 0000 \\
\hline $\operatorname{lnj} 2$ & 0000 \\
\hline $\operatorname{lnj} 3$ & 0000 \\
\hline Tol 1 & $0 \bullet 0$ \\
\hline Tol 2 & - \\
\hline Tol 3 & 000 \\
\hline Contra: Inj 1 & 0000 \\
\hline $\operatorname{lnj} 2$ & $0 \quad 00$ \\
\hline $\operatorname{lnj} 3$ & 0000 \\
\hline Tol 1 & 00 \\
\hline
\end{tabular}

E

Phc2 - Hypomethylated in injury

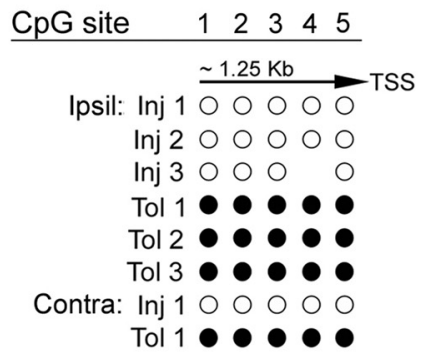

Figure 6. Verification of differentially methylated genes in injury and tolerance. $\boldsymbol{A}-\boldsymbol{E}$, Bisulfite sequencing of ipsilateral (Ipsil) and contralateral (Contra) CA3 subfields confirming differentially hypermethylated and hypomethylated genes in injury (Inj) and tolerance (Tol) for Gtf2i (A), Atp2c1 (B), Hmga2 (C), Cpne6 (D), and Phc2 (E). Filled circles represent methylated (pp sites, and open circles represent unmethylated $\mathrm{CpG}$ sites. Missing circles represent $\mathrm{CpG}$ sites for which methylation status could not be determined. Distance to the TSS from the first $\mathrm{CpG}$ site analyzed is indicated.

Table 3. Bisulfite validation of methylation status of genes in injury and tolerance

\begin{tabular}{llll}
\hline Gene ID & Size of PCR product ${ }^{a}$ & Number of CpG sites & Definitive methylation status assigned \\
\hline Atp2c1 & 240 & 18 & 15 of 18 \\
Cpne6 & 115 & 4 & 4 of 4 \\
Gtf2i & 307 & 34 & 28 of 34 \\
Hmga2 & 381 & 21 & 20 of 21 \\
Phc2 & 354 & 5 & 5 of 5 \\
\hline
\end{tabular}

aproduct size in basepairs.

The prominent methylation change caused by SE in both injury and tolerance mice was hypomethylation/demethylation of gene promoters. Demethylation of CpGs is also evident after electroconvulsive seizures (Guo et al., 2011b). Our data therefore emphasizes a dominance of expression-activating methylation changes after SE over gene silencing (Roopra et al., 2001; Urdinguio et al., 2009). Active demethylation of genes has emerged as an important epigenetic mechanism involved in the regulation of embryonic and CNS development, although the mechanisms of demethylation are not fully resolved (Weaver et al., 2004; Feng and Fan, 2009; Wu and Zhang, 2010). We did not see changes to protein levels of known demethylating enzymes (nor the DNA methylating enzymes Dnmt1, Dnmt3a, and Dnmt3b) after preconditioning. Nevertheless, the majority of differential hypermethylation events were found to occur in tolerance, not injury, although the number of genes in this dataset was relatively low considering the extent of gene suppression in epileptic tolerance (Jimenez-Mateos et al., 2008). Two of the differentially hypermethylated genes in tolerance (Cpne6 and Slc1a6) were previously 
A

Gtf2i
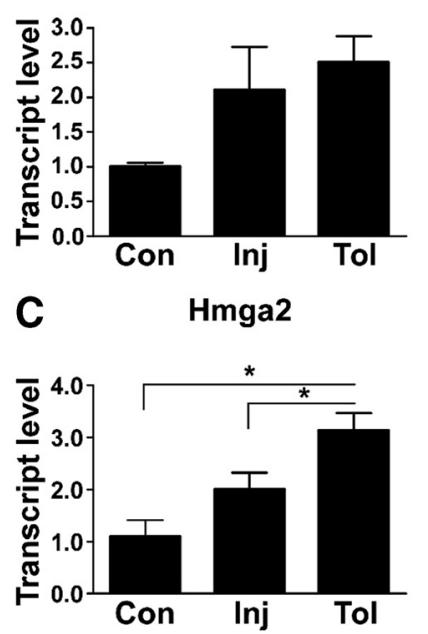

E

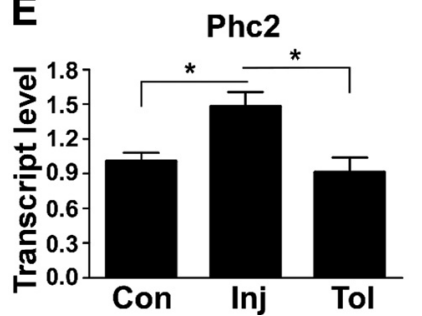

B

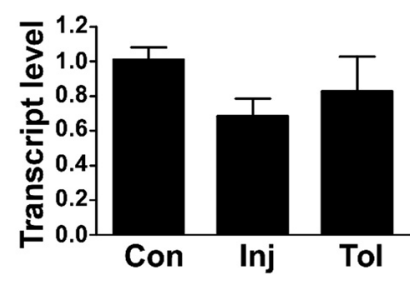

D

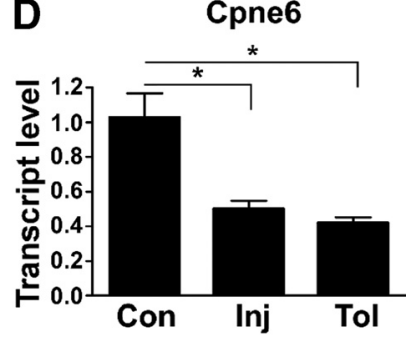

$\mathbf{F}$

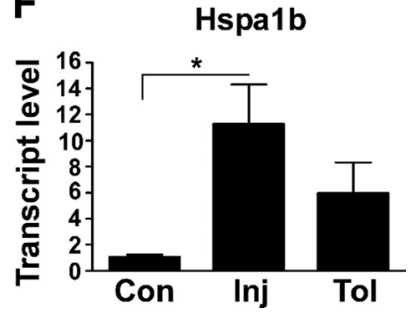

Figure 7. Tissue expression of genes hypermethylated and hypomethylated in injury (Inj) and tolerance (Tol). Graphs show mRNA expression levels (relative fold level) at $24 \mathrm{~h}$ measured by real-time qPCR for $G t f 2 i(\boldsymbol{A}$, hypermethylated in tolerance), Atp2C ( $\boldsymbol{B}$, hypermethylated in injury), Hmga2 ( $\boldsymbol{C}$, hypermethylated in tolerance), (pne6 ( $\boldsymbol{D}$, hypermethylated in tolerance), Phc2 (E, hypomethylated in injury) and $H$ spa $1 b$ ( $\boldsymbol{F}$, hypomethylated in injury) $\left({ }^{*} p<0.05, n=\right.$ 3-6 per group). Con, Control.

identified as differentially downregulated at the mRNA level in tolerance (Jimenez-Mateos et al., 2008). None of the differentially hypomethylated genes in tolerance had been found previously among differentially upregulated genes in tolerance (Jimenez-Mateos et al., 2008). The limited association between altered methylation state and gene expression in tolerance supports, therefore, mechanisms in addition to changed methylation as determinants of differential gene expression. Nevertheless, potential significance of the methylation profile in epileptic tolerance was emphasized by GO analysis, which highlighted differences in the cellular locations and molecular function of differentially methylated genes in injury and tolerance. For example, the majority of nucleus-associated genes in tolerance were hypermethylated, in contrast to the demethylation trends evident in injury, implying a role for these changes in transcription or other nuclear activities. Indeed, analysis of molecular function illustrated that the tolerance dataset included genes involved in DNA binding and transcriptional regulation, including Gtf2i, Hmga2, and Pold1, which may play an active role in the gene suppression evident in epileptic tolerance.

Studies in cancer have found clustering of hypermethylation sites within the genome and, in the case of neuroblastic tumors, toward the telomeric ends of chromosomes (Buckley et al., 2011). Our study shows that differential methylation events in injury and tolerance generally occur throughout the genome, with no enrichment for a particular chromosomal region, with a notable exception. Positional gene enrichment analyses indicated that a small region of chromosome 4, which encompassed Phc2 and

Tlr12, was significantly overrepresented in genes demethylated in injury. Toll-like receptors have been implicated previously in the neuroprotection evident in ischemic tolerance (Stevens et al., 2008; Marsh et al., 2009; Vartanian and Stenzel-Poore, 2010). Furthermore, Tlr4 expression is increased in human and mouse epileptic tissue, and TLR4-defective mice are resistant to KAinduced seizures (Maroso et al., 2010). Differential demethylation and expression of Phc2 in injury may also be important. Several members of the polycomb family have been shown recently to be differentially upregulated and essential for the establishment of ischemic tolerance (Stapels et al., 2010). These included the polycomb repressive complex 1 (PRC1) member $B M I 1$, which protects against chemical stress-induced cell death (Lee et al., 2008) and with which Phc2 has been shown to interact (Satijn et al., 1997). Initially, polycomb proteins were thought to regulate the transcription of only a few genes, including the Hox (homeotic) genes. However, the list of polycomb targeted genes has expanded in recent years to include genes encoding proteins involved in electron and glucose transport, as well as endopeptidases, oxidoreductases, and G-protein-coupled receptors (Bracken et al., 2006; Tolhuis et al., 2006). In the present study, a second polycomb gene, Suz12 (suppressor of zeste 12 homolog) was also identified as differentially hypomethylated in injury. Because differential hypomethylation of Phc2 and Suz12 occurred only in injury and not in epileptic tolerance, the results suggest that this family of transcriptional regulators may contribute to the ordinary control of gene expression in the wake of SE.

Most of the genes present in the unique differential methylation profiles of injury or tolerance have not been captured previously by microarray-based screening for seizure-regulated or epileptogenesis genes (Becker et al., 2003; Lukasiuk and Pitkänen, 2004; Gorter et al., 2006; Laurén et al., 2010; Wang et al., 2010). The present study therefore identifies potentially new genes regulated by seizures and the mechanism by which they may be regulated, in addition to identifying novel players in epileptic tolerance that may be interesting targets for neuroprotection and anti-epileptogenesis (Jimenez-Mateos and Henshall, 2009). The expression of several of these genes was investigated, and, in individual cases, promoter methylation was consistent with a role in the regulation of gene expression in epileptic tolerance and injury. However, gene expression did not always correlate with differential methylation state. Previously, gene-centric studies in epilepsy have highlighted direct links between promoter methylation and pathohistological findings. Increased promoter methylation is responsible for the downregulation of Reelin, which is associated with granule cell dispersion in human temporal lobe epilepsy (Kobow et al., 2009), and DNA methylation may regulate levels of brain-derived neurotrophic factor in animal models of epilepsy (Aid et al., 2007). In the context of the individual cases highlighted in our study, this emphasizes the impact even single gene methylation changes can exert on seizure pathophysiology.

Hippocampal damage is often bilateral in patients with unilateral temporal lobe epilepsy by clinical and neurophysiological criteria (Babb, 1991; Jokeit et al., 1999; Araújo et al., 2006). Furthermore, SE can lead to bilateral CA3 damage in humans (Fujikawa et al., 2000) and in animal models, transforming the contralateral hippocampus into an independent epileptogenic focus, capable of generating spontaneous and evoked seizures (Araki et al., 2002; Khalilov et al., 2003). A final observation in our study was the occurrence of bilateral hippocampal methylation changes. Bilateral changes are what would be expected if the preconditioning stimulus is contributing to differential methylation in tolerance because systemic KA would drive changes af- 
fecting both hippocampi. Bilateral methylation changes also support changes in DNA methylation being attributable to seizure activity alone, consistent with reports of activity-dependent DNA methylation changes during memory encoding (Miller and Sweatt, 2007). Bilateral DNA methylation changes also suggest that the genes affected may regulate processes other than cell death and survival decisions, leaving open contributions by other transcriptional control mechanisms to the neuroprotection in epileptic tolerance.

A direct assessment of the contribution of DNA hypermethylation to the transcriptional environment of tolerance requires the individual or combined manipulation of Dnmts. Dnmt1 levels can be depleted using 5-aza-2'-deoxycytidine (Christman, 2002). However, when used acutely, this DNA methyltransferase inhibitor is neuroprotective against excitotoxic injuries (Endres et al., 2000), which would complicate interpretation of its effects against tolerance. Surprisingly, genetic deletion of Dnmtl or Dnmt3a alone produces virtually no neuronal phenotype (Fan et al., 2001; Feng et al., 2010). Conditional mutants lacking both Dnmt1 and Dnmt3a display defects in synaptic plasticity, but their loss resulted in upregulation of only $0.26 \%$ of profiled genes in vivo (Feng et al., 2010). An evaluation of the impact of blocking components of DNA methylation or demethylation on otherwise hypermethylated or hypomethylated genes in tolerance may extend the present insights.

In summary, through genome-wide methylation analysis, we have identified unique profiles of differential methylation after $\mathrm{SE}$ and in epileptic tolerance. These profiles include many novel genes that have not been associated previously with epilepsy. Although differential hypermethylation was not substantial and is not likely to act as the sole molecular mechanism underlying gene suppression in epileptic tolerance, large contributions by a small number of genes remain possible. Together, our study identifies differential methylation of genes as a novel mechanism for endogenous programs of neuroprotection and the molecular environment impacted by SE.

\section{References}

Aid T, Kazantseva A, Piirsoo M, Palm K, Timmusk T (2007) Mouse and rat BDNF gene structure and expression revisited. J Neurosci Res 85:525-535.

Araki T, Simon RP, Taki W, Lan JQ, Henshall DC (2002) Characterization of neuronal death induced by focally evoked limbic seizures in the C57BL/6 mouse. J Neurosci Res 69:614-621.

Araújo D, Santos AC, Velasco TR, Wichert-Ana L, Terra-Bustamante VC, Alexandre V Jr, Carlotti CG Jr, Assirati JA Jr, Machado HR, Walz R, Leite JP, Sakamoto AC (2006) Volumetric evidence of bilateral damage in unilateral mesial temporal lobe epilepsy. Epilepsia 47:1354-1359.

Babb TL (1991) Bilateral pathological damage in temporal lobe epilepsy. Can J Neurol Sci 18:645-648.

Becker AJ, Chen J, Zien A, Sochivko D, Normann S, Schramm J, Elger CE, Wiestler OD, Blümcke I (2003) Correlated stage- and subfieldassociated hippocampal gene expression patterns in experimental and human temporal lobe epilepsy. Eur J Neurosci 18:2792-2802.

Bracken AP, Dietrich N, Pasini D, Hansen KH, Helin K (2006) Genomewide mapping of Polycomb target genes unravels their roles in cell fate transitions. Genes Dev 20:1123-1136.

Buckley PG, Das S, Bryan K, Watters KM, Alcock L, Koster J, Versteeg R, Stallings RL (2011) Genome-wide DNA methylation analysis of neuroblastic tumors reveals clinically relevant epigenetic events and large-scale epigenomic alterations localized to telomeric regions. Int J Cancer 128:2296-2305

Christman JK (2002) 5-Azacytidine and 5-aza-2'-deoxycytidine as inhibitors of DNA methylation: mechanistic studies and their implications for cancer therapy. Oncogene 21:5483-5495.

Dallosso AR, Hancock AL, Szemes M, Moorwood K, Chilukamarri L, Tsai HH, Sarkar A, Barasch J, Vuononvirta R, Jones C, Pritchard-Jones K,
Royer-Pokora B, Lee SB, Owen C, Malik S, Feng Y, Frank M, Ward A, Brown KW, Malik K (2009) Frequent long-range epigenetic silencing of protocadherin gene clusters on chromosome $5 \mathrm{q} 31$ in Wilms' tumor. PLoS Genet 5:e1000745.

Das S, Foley N, Bryan K, Watters KM, Bray I, Murphy DM, Buckley PG, Stallings RL (2010) MicroRNA mediates DNA demethylation events triggered by retinoic acid during neuroblastoma cell differentiation. Cancer Res 70:7874-7881.

De Preter K, Barriot R, Speleman F, Vandesompele J, Moreau Y (2008) Positional gene enrichment analysis of gene sets for high-resolution identification of overrepresented chromosomal regions. Nucleic Acids Res 36:e43.

Dirnagl U, Becker K, Meisel A (2009) Preconditioning and tolerance against cerebral ischaemia: from experimental strategies to clinical use. Lancet Neurol 8:398-412.

Endres M, Meisel A, Biniszkiewicz D, Namura S, Prass K, Ruscher K, Lipski A, Jaenisch R, Moskowitz MA, Dirnagl U (2000) DNA methyltransferase contributes to delayed ischemic brain injury. J Neurosci 20:3175-3181.

Fan G, Beard C, Chen RZ, Csankovszki G, Sun Y, Siniaia M, Biniszkiewicz D, Bates B, Lee PP, Kuhn R, Trumpp A, Poon C, Wilson CB, Jaenisch R (2001) DNA hypomethylation perturbs the function and survival of CNS neurons in postnatal animals. J Neurosci 21:788-797.

Feng J, Fan G (2009) The role of DNA methylation in the central nervous system and neuropsychiatric disorders. Int Rev Neurobiol 89:67-84.

Feng J, Zhou Y, Campbell SL, Le T, Li E, Sweatt JD, Silva AJ, Fan G (2010) Dnmt1 and Dnmt3a maintain DNA methylation and regulate synaptic function in adult forebrain neurons. Nat Neurosci 13:423-430.

Frigola J, Song J, Stirzaker C, Hinshelwood RA, Peinado MA, Clark SJ (2006) Epigenetic remodeling in colorectal cancer results in coordinate gene suppression across an entire chromosome band. Nat Genet 38:540-549.

Fujikawa DG, Itabashi HH, Wu A, Shinmei SS (2000) Status epilepticusinduced neuronal loss in humans without systemic complications or epilepsy. Epilepsia 41:981-991.

Gidday JM (2006) Cerebral preconditioning and ischaemic tolerance. Nat Rev Neurosci 7:437-448.

Gorter JA, van Vliet EA, Aronica E, Breit T, Rauwerda H, Lopes da Silva FH, Wadman WJ (2006) Potential new antiepileptogenic targets indicated by microarray analysis in a rat model for temporal lobe epilepsy. J Neurosci 26:11083-11110.

Guo JU, Su Y, Zhong C, Ming GL, Song H (2011a) Hydroxylation of 5 -methylcytosine by TET1 promotes active DNA demethylation in the adult brain. Cell 145:423-434.

Guo JU, Ma DK, Mo H, Ball MP, Jang MH, Bonaguidi MA, Balazer JA, Eaves HL, Xie B, Ford E, Zhang K, Ming GL, Gao Y, Song H (2011b) Neuronal activity modifies the DNA methylation landscape in the adult brain. Nat Neurosci 14:1345-1351.

Hatazaki S, Bellver-Estelles C, Jimenez-Mateos EM, Meller R, Bonner C, Murphy N, Matsushima S, Taki W, Prehn JH, Simon RP, Henshall DC (2007) Microarray profile of seizure damage-refractory hippocampal $\mathrm{CA} 3$ in a mouse model of epileptic preconditioning. Neuroscience 150:467-477.

Hiura H, Sugawara A, Ogawa H, John RM, Miyauchi N, Miyanari Y, Horiike T, Li Y, Yaegashi N, Sasaki H, Kono T, Arima T (2010) A tripartite paternally methylated region within the Gpr1-Zdbf2 imprinted domain on mouse chromosome 1 identified by meDIP-on-chip. Nucleic Acids Res 38:4929-4945.

Iraola-Guzman S, Estivill X, Rabionet R (2011) DNA methylation in neurodegenerative disorders: a missing link between genome and environment? Clin Genet 80:1-14.

Jaenisch R, Bird A (2003) Epigenetic regulation of gene expression: how the genome integrates intrinsic and environmental signals. Nat Genet [Suppl] 33:245-254.

Jimenez-Mateos EM, Henshall DC (2009) Seizure preconditioning and epileptic tolerance: models and mechanisms. Int J Physiol Pathophysiol Pharmacol 1:180-191.

Jimenez-Mateos EM, Hatazaki S, Johnson MB, Bellver-Estelles C, Mouri G, Bonner C, Prehn JH, Meller R, Simon RP, Henshall DC (2008) Hippocampal transcriptome after status epilepticus in mice rendered seizure damage-tolerant by epileptic preconditioning features suppressed calcium and neuronal excitability pathways. Neurobiol Dis 32:442-453.

Johnson MB, Simon RP (2009) Endogenous neuroprotective mechanisms in the brain. Epilepsia 50 [Suppl 12]:3-4. 
Jokeit H, Ebner A, Arnold S, Schüller M, Antke C, Huang Y, Steinmetz H, Seitz RJ, Witte OW (1999) Bilateral reductions of hippocampal volume, glucose metabolism, and wada hemispheric memory performance are related to the duration of mesial temporal lobe epilepsy. J Neurol 246:926-933.

Khalilov I, Holmes GL, Ben-Ari Y (2003) In vitro formation of a secondary epileptogenic mirror focus by interhippocampal propagation of seizures. Nat Neurosci 6:1079-1085.

Kin T, Ono Y (2007) Idiographica: a general-purpose web application to build idiograms on-demand for human, mouse and rat. Bioinformatics 23:2945-2946.

Kobow K, Jeske I, Hildebrandt M, Hauke J, Hahnen E, Buslei R, Buchfelder M, Weigel D, Stefan H, Kasper B, Pauli E, Blümcke I (2009) Increased reelin promoter methylation is associated with granule cell dispersion in human temporal lobe epilepsy. J Neuropathol Exp Neurol 68:356-364.

Laurén HB, Lopez-Picon FR, Brandt AM, Rios-Rojas CJ, Holopainen IE (2010) Transcriptome analysis of the hippocampal CA1 pyramidal cell region after kainic acid-induced status epilepticus in juvenile rats. PLoS One 5:e10733.

Lee K, Adhikary G, Balasubramanian S, Gopalakrishnan R, McCormick T, Dimri GP, Eckert RL, Rorke EA (2008) Expression of Bmi-1 in epidermis enhances cell survival by altering cell cycle regulatory protein expression and inhibiting apoptosis. J Invest Dermatol 128:9-17.

Levenson JM, Roth TL, Lubin FD, Miller CA, Huang IC, Desai P, Malone LM, Sweatt JD (2006) Evidence that DNA (cytosine-5) methyltransferase regulates synaptic plasticity in the hippocampus. J Biol Chem 281:15763-15773.

Lukasiuk K, Pitkänen A (2004) Large-scale analysis of gene expression in epilepsy research: is synthesis already possible? Neurochem Res 29:1169-1178.

Ma DK, Jang MH, Guo JU, Kitabatake Y, Chang ML, Pow-Anpongkul N, Flavell RA, Lu B, Ming GL, Song H (2009) Neuronal activity-induced Gadd45b promotes epigenetic DNA demethylation and adult neurogenesis. Science 323:1074-1077.

Maroso M, Balosso S, Ravizza T, Liu J, Aronica E, Iyer AM, Rossetti C, Molteni M, Casalgrandi M, Manfredi AA, Bianchi ME, Vezzani A (2010) Toll-like receptor 4 and high-mobility group box-1 are involved in ictogenesis and can be targeted to reduce seizures. Nat Med 16:413-419.

Marsh BJ, Williams-Karnesky RL, Stenzel-Poore MP (2009) Toll-like receptor signaling in endogenous neuroprotection and stroke. Neuroscience 158:1007-1020.

Meaburn KJ, Misteli T (2007) Cell biology: chromosome territories. Nature 445:379-781.

Meaburn KJ, Misteli T (2008) Locus-specific and activity-independent gene repositioning during early tumorigenesis. J Cell Biol 180:39-50.

Mill J, Tang T, Kaminsky Z, Khare T, Yazdanpanah S, Bouchard L, Jia P, Assadzadeh A, Flanagan J, Schumacher A, Wang SC, Petronis A (2008) Epigenomic profiling reveals DNA-methylation changes associated with major psychosis. Am J Hum Genet 82:696-711.

Miller CA, Sweatt JD (2007) Covalent modification of DNA regulates memory formation. Neuron 53:857-869.

Morahan JM, Yu B, Trent RJ, Pamphlett R (2009) A genome-wide analysis of brain DNA methylation identifies new candidate genes for sporadic amyotrophic lateral sclerosis. Amyotroph Lateral Scler 10:418-429.

Murphy DM, Buckley PG, Bryan K, Das S, Alcock L, Foley NH, Prenter S, Bray I, Watters KM, Higgins D, Stallings RL (2009) Global MYCN transcription factor binding analysis in neuroblastoma reveals association with distinct E-box motifs and regions of DNA hypermethylation. PLoS One 4:e8154.

Novak P, Jensen T, Oshiro MM, Watts GS, Kim CJ, Futscher BW (2008) Agglomerative epigenetic aberrations are a common event in human breast cancer. Cancer Res 68:8616-8625.

Ragoczy T, Telling A, Sawado T, Groudine M, Kosak ST (2003) A genetic analysis of chromosome territory looping: diverse roles for distal regulatory elements. Chromosome Res 11:513-525.

Ragoczy T, Bender MA, Telling A, Byron R, Groudine M (2006) The locus control region is required for association of the murine beta-globin locus with engaged transcription factories during erythroid maturation. Genes Dev 20:1447-1457.

Robertson KD (2005) DNA methylation and human disease. Nat Rev Genet 6:597-610.

Roopra A, Huang Y, Dingledine R (2001) Neurological disease: listening to gene silencers. Mol Interv 1:219-228.

Satijn DP, Gunster MJ, van der Vlag J, Hamer KM, Schul W, Alkema MJ, Saurin AJ, Freemont PS, van Driel R, Otte AP (1997) RING1 is associated with the polycomb group protein complex and acts as a transcriptional repressor. Mol Cell Biol 17:4105-4113.

Stapels M, Piper C, Yang T, Li M, Stowell C, Xiong ZG, Saugstad J, Simon RP, Geromanos S, Langridge J, Lan JQ, Zhou A (2010) Polycomb group proteins as epigenetic mediators of neuroprotection in ischemic tolerance. Sci Signal 3:ra15.

Stenzel-Poore MP, Stevens SL, King JS, Simon RP (2007) Preconditioning reprograms the response to ischemic injury and primes the emergence of unique endogenous neuroprotective phenotypes: a speculative synthesis. Stroke 38:680-685.

Stevens SL, Ciesielski TM, Marsh BJ, Yang T, Homen DS, Boule JL, Lessov NS, Simon RP, Stenzel-Poore MP (2008) Toll-like receptor 9: a new target of ischemic preconditioning in the brain. J Cereb Blood Flow Metab 28:1040-1047.

Tanaka K, Jimenez-Mateos EM, Matsushima S, Taki W, Henshall DC (2010) Hippocampal damage after intra-amygdala kainic acid-induced status epilepticus and seizure preconditioning-mediated neuroprotection in SJL mice. Epilepsy Res 88:151-161.

Tolhuis B, de Wit E, Muijrers I, Teunissen H, Talhout W, van Steensel B, van Lohuizen M (2006) Genome-wide profiling of PRC1 and PRC2 Polycomb chromatin binding in Drosophila melanogaster. Nat Genet 38:694-699.

Urdinguio RG, Sanchez-Mut JV, Esteller M (2009) Epigenetic mechanisms in neurological diseases: genes, syndromes, and therapies. Lancet Neurol 8:1056-1072.

Vartanian K, Stenzel-Poore M (2010) Toll-like receptor tolerance as a mechanism for neuroprotection. Transl Stroke Res 1:252-260.

Wang YY, Smith P, Murphy M, Cook M (2010) Global expression profiling in epileptogenesis: does it add to the confusion? Brain Pathol 20:1-16.

Weaver IC, Cervoni N, Champagne FA, D’Alessio AC, Sharma S, Seckl JR, Dymov S, Szyf M, Meaney MJ (2004) Epigenetic programming by maternal behavior. Nat Neurosci 7:847-854.

Wu SC, Zhang Y (2010) Active DNA demethylation: many roads lead to Rome. Nat Rev Mol Cell Biol 11:607-620.

Wu X, Rauch TA, Zhong X, Bennett WP, Latif F, Krex D, Pfeifer GP (2010) CpG island hypermethylation in human astrocytomas. Cancer Res 70: $2718-2727$. 